\title{
Early risk assessment of circulating endothelial progenitor cells and plasma stromal cell-derived factor- 1 for nondisabling ischemic cerebrovascular events
}

\author{
Wang Zhao ${ }^{1}$, Libo Zhao', Juan Liao ${ }^{2}$, Yong Luo ${ }^{3^{*}}$ and Lanying $\mathrm{He}^{4}$
}

\begin{abstract}
Background: Endothelial progenitor cells (EPCS) play an important role in ischemic stroke. However, there are few studies on the relationship between EPC and nondisabling ischemic cerebrovascular events. Our aim was to investigate the association of EPCS and SDF-1 (serum stromal cell-derived factor-1) with NICE (nondisabling ischemic cerebrovascular events).

Methods: TIA (transient ischemic attack) and minor stroke patients (153 in total) who had an onset of symptoms within 1 day were consecutively collected. 83 of the patients were categorized into the HR-NICE (high-risk nondisabling ischemic cerebrovascular event) group, and 70 of the patients were in the NHR-NICE (non-high-risk nondisabling ischemic cerebrovascular events) group. Adopted FCM (flow cytometry) was used to measure EPCs, taking double-positive CD34/KDR as EPCs. ELISA was used to measure the concentrations of serum SDF-1 and VEGF (vascular endothelial growth factor). By the sequence of admission time, 15 patients were selected separately from the HR-NICE group and NHR-NICE group, and another 15 healthy volunteers were chosen as the NC (Normal Control) group. The MTT method was used to measure the proliferation of EPCs of peripheral blood in all groups, and the Boyden chamber was used to measure the migration of EPCS.

Results: Compared with the NHR-NICE group, the HR-NICE group was older and contained more patients with hypertension and diabetes. Triglyceride, total cholesterol, and low-density lipoprotein in the HR-NICE group were also higher. For factors such as smoking, BMI (body mass index), and HCY (homocysteine), there were no significant differences $(P>0.05)$. Circulating EPCS, SDF-1, and VEGF in the NHR-NICE group were all higher. According to the multifactor regression analysis, age, hypertension, diabetes, total cholesterol, EPCs, and SDF-1 are independent risk factors for HR-NICE. For EPCS of 48-h isolated cultures, proliferation and migration were observed to be weakened compared with those of the NC group $(P<0.05)$. EPCs in HR-NICE group had lower proliferation and migration than those in NHR-NICE group $(P<0.01)$.

Conclusions: For TIA and minor stroke patients, circulating EPCs and serum SDF-1 concentrations can be used to prognose HR-NICE. Factors that lead to high-risk NICE might be relevant to the decrease in proliferation and migration of circulating EPCS.
\end{abstract}

Keywords: Endothelial progenitor cells, Stromal cell-derived factor-1, TIA;minor stroke, Nondisabling ischemic cerebrovascular events

\footnotetext{
* Correspondence: Luoyong1998@163.com

${ }^{3}$ Department of Neurology, The First Affiliated Hospital of Chongqing

Medical University, Chongqing 400016, China

Full list of author information is available at the end of the article
}

(c) The Author(s). 2019 Open Access This article is distributed under the terms of the Creative Commons Attribution 4.0 International License (http://creativecommons.org/licenses/by/4.0/), which permits unrestricted use, distribution, and reproduction in any medium, provided you give appropriate credit to the original author(s) and the source, provide a link to the Creative Commons license, and indicate if changes were made. The Creative Commons Public Domain Dedication waiver (http://creativecommons.org/publicdomain/zero/1.0/) applies to the data made available in this article, unless otherwise stated. 


\section{Background}

Endothelial progenitor cells (EPCs) play an important role in tissue repair in ischemic organs. Many studies have been conducted to demonstrate that endothelial progenitor cells promote ischemic tissue angiogenesis after stroke. However, there are few studies on the relationship between EPC and nondisabling ischemic cerebrovascular events. According to CNSR II (The China National Stroke Registry II), 23,900,000 patients suffer from TIA [1], and minor stroke patients account for $46.4 \%$ of all ischemic stroke patients. We should treat TIA and minor stroke as the most important group for prevention and treatment. The imbalance of the amount of vessel damage and the abilities of the repair system can lead to atherosclerosis and then cerebral infarction. Regarding vessel repair, previous studies have shown that plasma SDF-1 has a positive impact on the long-term prognosis of ACI (acute cerebral infarction) [2]. After ACI, plasma SDF-1 will increase, and a large amount of EPCs in peripheral blood will participate in the regeneration and repair of vessels [3]. When EPCs were found to be increased in patients who suffered TIA for the first time, the possibility of experiencing an ischemic attack in the future wasn't increased [4]. Based on previous studies, we are enlightened that differences in the quantity and quality of circulating EPCs as well as serum SDF-1 levels might exist in patients with TIA and minor stroke. These differences might be used to differentiate NHR-NICE and HR-NICE, where HR-NICE may develop into DICE (disabling ischemic cerebrovascular events). Therefore, circulating EPCs and SDF-1 levels might be able to further prognose high-risk cerebral stroke for NICE patients. China is one of the countries that suffers most from cerebral stroke [5], with an enormous amount of HR-NICE patients; therefore, it is very beneficial to study the relationship between EPCs, SDF-1 and NICE.

\section{Methods}

Research subjects

A total of 186 TIA and minor stroke patients were consecutively collected from June 2016 to June 2018 in the Neurology Department of the Affiliated Hospital of Chongqing Medical University, from both out-patient service and hospitalization. All patients developed morbidity within 1 day. Their ages ranged from 18 to 80 years; 12 were excluded cases, and 21 were shedding cases. The NC group consisted of 15 healthy volunteers who were openly recruited after an official announcement from the hospital during the same time period. Their genders and ages were matched to the other two groups. Finally, 153 patients and 15 healthy volunteers were included in the analysis. Among these 153 patients, there were 83 HR-NICE patients and 70 NHR-NICE patients. Blood samples were taken immediately after admission for TIA and minor stroke patients, and FCM was adopted to measure the amount of circulating EPCs. Using ELISA, the concentrations of serum SDF-1 and VEGF were measured. For the 15 patients in the NC group, only circulating EPCs were extracted. Meanwhile, circulating EPCs were extracted from the first 15 patients in both the HR-NICE and NHR-NICE groups. The MTT method was used to measure the proliferation of EPCs of peripheral blood in all groups, and the Boyden chamber was used to measure the migration of EPCs. NICE refers to ischemic cerebrovascular events that leave no significant disability after morbidity, which includes three types of patients: 1 . those who had a TIA; 2. those who had a minor stroke; and 3. those whose symptoms rapidly alleviated and left no significant disability after morbidity. In this research, the definition of HR-NICE is as follows: high-risk TIA (ABCD2 score $\geq 4$ points) and minor stroke patients who developed morbidity within $24 \mathrm{~h}$ [1]. The definition of NHR-NICE is TIA (ABCD2 score $<4$ points). Participants were excluded if they had any history of the following: trauma, blood system diseases, renal insufficiency, inflammation, ulcer, abnormal liver function, malignant tumors, myocardial infarction, angina, atrial fibrillation, recent surgical history, and usage of statins or EPO within 2 months before morbidity. Minor stroke can be defined as NIHSS score $\leq 3$; The definition of "no significant disability after morbidity" is as follows: severe symptoms during morbidity but the symptoms alleviated as TIA or minor stroke as in treatment. This research was approved by the Ethics Committee of Yongchuan Hospital of Chongqing Medical University. All patients or their relatives signed an informed consent form.

\section{Measure of circulating EPCs}

$\mathrm{CD} 34+/ \mathrm{KDR}+$ were adopted as a marker of circulating EPCs [6]. After admission, $8 \mathrm{~mL}$ of antecubital venous blood was extracted and added to a buffer solution with $3.8 \%$ heparin. A density gradient centrifugation was used to obtain a monocyte layer and to adjust the density of the cells to $1 \times 10^{6} / \mathrm{ml} .20 \mu \mathrm{l}$ of Mouse Anti-Human CD34 monoclonal IgG1 (Southern Biotech Inc., U.S.) was added with a PE mark and $10 \mu \mathrm{l}$ of Mouse Anti-Human KDR monoclonal IgG1 (R\&D Inc., U.S.) was added with an FITC mark. These were then incubated at room temperature without light for $30 \mathrm{~min}$. Next, the samples were centrifuged at $4{ }^{\circ} \mathrm{C}$ for $5 \mathrm{~min}$ at $1500 \mathrm{rpm} / \mathrm{min}$, and the supernatant was removed and washed twice with PBS. Then, FCM was used to conduct quantitative analysis. The percentage of CD34+/KDR+ cells account for monocyte cells and were used to measure the level of EPCs. 


\section{Identification of EPCs}

Cultivated monocytes were obtained by density gradient centrifugation in M199 medium (Hyclone, USA) until cell climbing on the 7th day. These were fixed with $2 \%$ paraformaldehyde for $15 \mathrm{~min}$ and washed in PBS 3 times. Fifty microliters of DIL-acLDL $(10 \mu \mathrm{g} / \mathrm{ml})$ was added then the cells were cultivated at $37^{\circ} \mathrm{C}$ in an incubator for $1 \mathrm{~h}$. Next, they were washed twice with PBS, and fixed with $2 \%$ paraformaldehyde for $10 \mathrm{~min}$ at room temperature. Fifty microliters of FITC-UEA-Lectin $(20 \mu \mathrm{g} / \mathrm{ml})$ was added, and then the cells were cultivated for $2 \mathrm{~h}$ at $4{ }^{\circ} \mathrm{C}$ without light and washed with PBS three times. The cells were identified by laser confocal microscopy, where FITC-Lectin positive was in green fluorescence, DIL-acLDL positive was in red fluorescence, and the two target cells were yellow, which were the EPCs under differentiation.

\section{Proliferation of EPCs}

The 3-(4,5-dimethylthiazol-2-yl)-2,5-diphenyltetrazolium bromide (MTT) assay was performed according to the protocol of the manufacturer to determine the proliferation of EPCs [7]. The density of cultured EPCs was adjusted for $48 \mathrm{~h}$ to $1 \times 10^{6} / \mathrm{ml}$, and $100 \mu \mathrm{l}$ of EPCs were inoculated into the culture plate coated with human fibronectin. Then, $20 \mu \mathrm{l}$ of MTT solution $(5 \mathrm{mg} / \mathrm{ml})$ was added to each hole and cultivated for $6 \mathrm{~h}$. The supernatant was removed. Then, $150 \mu \mathrm{l}$ of dimethyl sulfoxide was added to each hole and oscillated for $10 \mathrm{~min}$. The absorbance was measured at $490 \mathrm{~nm}$ by automatic enzyme labeling. For the clonogenic assay, the cells were seeded in $60 \mathrm{~mm}$ dishes (1000 cells/plate). Twelve hours after seeding, three groups of cells were allowed to grow until visible colonies appeared. The colonies were stained with $0.01 \%$ crystal violet (Sigma, St. Louis, MO) and counted under a microscope.

\section{Migration of EPCs}

Cell migration was quantified using a Boyden chamber. Briefly, the density of the EPCs cultured for $48 \mathrm{~h}$ was adjusted to $1 \times 10^{6} / \mathrm{ml}$. A $50 \mu \mathrm{l}$ cell suspension was added to the upper chamber of the Boyden chamber. Then, $25 \mu \mathrm{l}$ of culture medium and VEGF $(50 \mathrm{ng} / \mathrm{ml})$ were added to the lower chamber of the Boyden chamber. Cells were cultivated in an incubator for $6 \mathrm{~h}$. Then, the cells were stained at high magnification. Immobile cells were scraped off the membrane, fixed with methanol, Giemsa stained, and counted under a high-power lens.

\section{Measure concentrations of serum SDF-1 and VEGF}

Three milliliters of antecubital venous blood was extracted and added to a buffer solution with $3.8 \%$ heparin. Then, the solution was centrifuged at $4{ }^{\circ} \mathrm{C}$ for $15 \mathrm{~min}$ at $3000 \mathrm{rpm} / \mathrm{min}$, and the supernatant was collected and kept it in $\mathrm{a}-80^{\circ} \mathrm{C}$ freezer. ELISA was performed according to the protocol of the manufacturer to determine the concentration of serum SDF-1 and VEGF.

\section{Statistical analysis}

The SPSS version 21.0 statistics software was used for analysis. The continuous variable is expressed as the mean \pm standard deviation, and the categorical variables are expressed as percentages. Chi-square test, $\mathrm{T}$ test and ANOVA (analysis of variance) were used to compare the differences among the groups. The relationship between risk factors for traditional cerebrovascular diseases, EPCs, SDF-1, VEGF and NICE was evaluated by logistic regression analysis. $P<0.05$ is taken to show statistical significance.

\section{Results}

\section{Baseline characteristics}

The comparison of clinical data between the NHR-NICE and HR-NICE groups is in Table 1 . There were 85 males and 68 females in the 153 TIA and minor stroke cases, whose average age was 59.15 years old. However, patients in the HR-NICE group were elderly and had more hypertension and diabetes $(P<0.01)$. The laboratory data showed that compared with the NHR-NICE group, patients in HR-NICE had higher levels of peripheral blood triglyceride, total cholesterol, and low-density lipoprotein. Regarding the other variables such as the sampling time, gender, smoking, BMI (Body Mass Index), and

Table 1 Clinical and laboratory data of NHR-NICE and HR-NICE group

\begin{tabular}{llll}
\hline & NHR-NICE(70) & HR-NICE $(83)$ & $P$ \\
\hline Time to sampling(h) & $10.69 \pm 5.00$ & $9.98 \pm 4.69$ & 0.370 \\
Age (year) & $56.50 \pm 8.16$ & $62.63 \pm 5.29$ & $<0.01$ \\
Male n (\%) & $40(57.14 \%)$ & $45(54.22 \%)$ & 0.719 \\
Hypertension n (\%) & $15(21.43 \%)$ & $46(55.42 \%)$ & $<0.01$ \\
Diabetes n (\%) & $7(10.00 \%)$ & $33(39.76 \%)$ & $<0.01$ \\
Smoking n (\%) & $28(40.00 \%)$ & $24(28.92 \%)$ & 0.149 \\
BMI 24 n (\%) & $27(38.57 \%)$ & $36(43.37)$ & 0.548 \\
TG (mmol/L) & $2.14 \pm 0.59$ & $2.44 \pm 0.59$ & $<0.01$ \\
TC (mmol/L) & $5.32 \pm 0.74$ & $5.67 \pm 0.74$ & $<0.01$ \\
LDL (mmol/L) & $3.42 \pm 0.60$ & $3.64 \pm 0.70$ & 0.018 \\
HCY umol/L & $14.48 \pm 4.70$ & $14.30 \pm 5.79$ & 0.514 \\
EPCs(EPCs/PMNC,\%oo) & $5.75 \pm 0.97$ & $4.09 \pm 0.77$ & $<0.01$ \\
SDF-1 (pg/ml) & $470.30 \pm 20.14$ & $755.12 \pm 29.67$ & $<0.01$ \\
VEGF (pg/ml) & $70.97 \pm 3.27$ & $83.28 \pm 2.36$ & $<0.01$ \\
\hline
\end{tabular}

Time to sampling: time from onset to collect blood sample;BMI Body Mass Index, TG Triglyceride, TC Total Cholesterol, LDL Low Density Lipoprotein, EPCS Endothelial Progenitor Cells, SDF-1 Stromal Cell-Derived Factor-1, VEGF, Vascular Endothelial Growth Factor 
$\mathrm{HCY}$ (homocysteine), there were no significant differences between the two groups $(P>0.05)$.

\section{Expression of EPCs, SDF-1 and VEGF in the NHR-NICE group and HR-NICE group}

The expression of EPCs, SDF-1 and VEGF in the NHR-NICE group and HR-NICE group is shown in Table 1 above. The data show that the circulating EPCs in the NHR-NICE group accounted for 5.75/000 of monocytes (Fig. 1a), while those in the HR-NICE group accounted for 4.09/000 (Fig. 1b). The mean values of serum SDF-1 in the two groups were $470.30 \mathrm{pg} / \mathrm{ml}$ and $755.12 \mathrm{pg} / \mathrm{ml}$ and inter-assay CV of $4.1 \%$, respectively. The mean serum VEGF values of the two groups were $70.97 \mathrm{pg} / \mathrm{ml}$ and $83.28 \mathrm{pg} / \mathrm{ml}$ and inter-assay CV of $3.7 \%$, respectively. In addition, the intra-assay $\mathrm{CV}$ of serum SDF in the NHR-NICE group and HR-NICE group were 4.3 and $3.9 \%$, the intra-assay CV of serum VEGF in the two groups were 4.6 and $2.8 \%$. The difference between the two groups is significant $(P<0.01)$.

\section{Analysis of related risk factors of NICE}

Univariate logistic regression analysis screened for possible variables, and the results showed that age, hypertension, diabetes, triglycerides, total cholesterol, low-density lipoprotein, EPCs, SDF-1, VEGF were associated with HR-NICE. However, the risk factors for traditional atherosclerosis include obesity, smoking, and homocysteine, so BMI, smoking, and homocysteine are also included in the multivariate regression analysis. After adjusting for age, BMI, hypertension, diabetes, smoking, triglycerides, total cholesterol, low-density lipoprotein, homocysteine, EPCs, SDF-1, and VEGF for multivariate logistic regression analysis, the results showed the following: age (OR:1.134, 95\% CI: 1.030 $1.249, P=0.011$ ), hypertension (OR: $10.798,95 \% \mathrm{CI}$ : 2.174-53.622, $P=0.004$ ), diabetes (OR: $11.630,95 \% \mathrm{CI}$ :
1.487-90.941, $P=0.019)$, TC (OR: $2.416,95 \%$ CI: $0.971-$ 6.010, $P=0.058$ ), EPCs (OR: 0.067, 95\% CI: 0.023-0.198, $P<0.01$ ), and SDF-1 (OR: 1.007, 95\% CI: 1.003-1.011, P $<0.01)$ are all independent risk factors for HR-NICE (Table 2).

\section{Identification, proliferation and migration of EPCs}

EPC double phagocytosis experiments showed that FITC-Lectin was positive when green fluorescence was present (Fig. 2a), DIL-acLDL was positive when red fluorescence was present (Fig. 2b), and double-labeled cells were yellow for the differentiation of EPCs (Fig. 2c). Peripheral blood was isolated and cultured for $48 \mathrm{~h}$ in EPCs. An MTT assay was used to detect the proliferation and migration ability of each group. The results showed that compared with the NC group, the cell proliferation abilities of the HR-NICE group and the NHR-NICE group were inhibited, and the difference was very significant $(P<0.01$, Fig. 3a, b). The cell migration ability of the HR-NICE group was weakened $(\mathrm{P}<0.01$, Fig. 3c, d). The cell migration ability of the NHR-NICE group was weaker than that of the $\mathrm{NC}$ group, and the difference was significant $(P<0.05)$. Compared with the NHR-NICE group, the cell proliferation and migration ability of the HR-NICE group was decreased $(P<0.01)$.

\section{Discussion}

The regeneration and repair of blood vessels after ischemic stroke have been the subjects of many studies. In 2010, the concept of minor stroke was proposed, and a stroke with an NIHSS score of less than 3 was classified as minor stroke [8].

In 2016, China published the "Guidelines for the diagnosis and treatment of high-risk nondisabling ischemic cerebrovascular events". Most of the nondisabling ischemic cerebrovascular events were TIA and minor stroke. At present, a variety of factors can predict the risk of
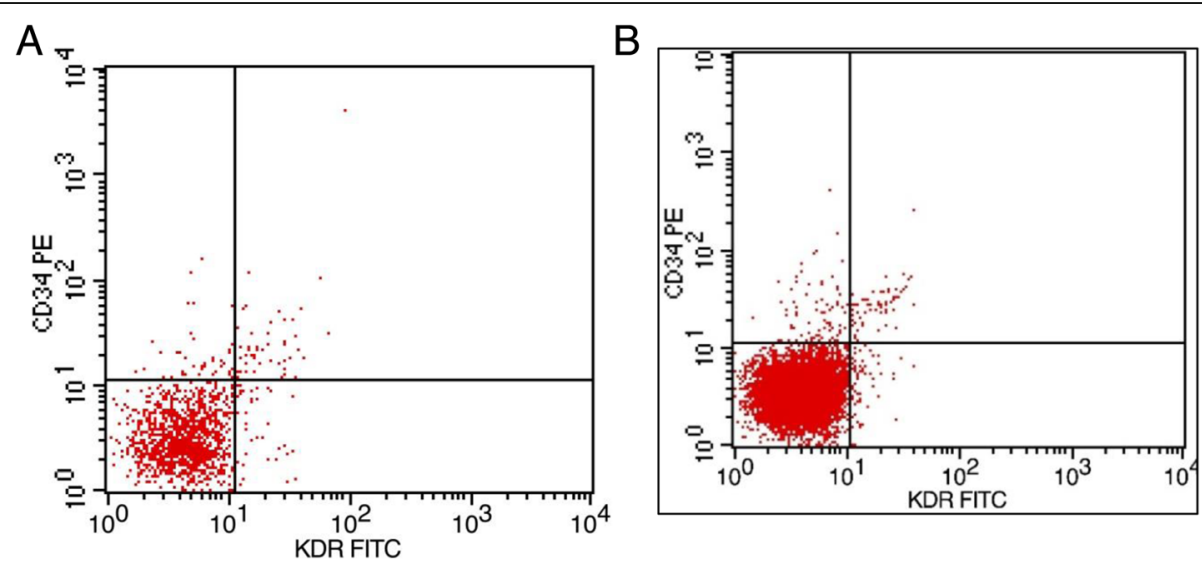

Fig. 1 Flow cytometry results revealed double-positive CD34/KDR cells in each group: in the HR-NICE group (Fig. 1a) and the NHR-NICE group (Fig. 1b) 
Table 2 Analysis of related risk factors of HR-NICE

\begin{tabular}{llll}
\hline Variables & $\mathrm{P}$ & $\mathrm{OR}$ & $95 \% \mathrm{Cl}$ \\
\hline Univariate analysis & & & \\
Age & $<0.01$ & 1.145 & $1.075-1.218$ \\
Gender & 0.717 & 1.126 & $0.593-2.137$ \\
IBM & 0.548 & 1.220 & $0.638-2.332$ \\
Hypertension & $<0.01$ & 0.219 & $0.107-0.449$ \\
Diabetes & $<0.01$ & 5.940 & $2.424-14.553$ \\
Smoking & 0.151 & 0.610 & $0.311-1.197$ \\
TG & 0.002 & 2.517 & $1.384-4.578$ \\
TC & 0.005 & 1.897 & $1.214-2.966$ \\
LDL & 0.040 & 1.723 & $1.024-2.899$ \\
Homocysteine & 0.836 & 0.994 & $0.936-1.055$ \\
EPCS & $<0.01$ & 0.123 & $0.065-0.233$ \\
SDF-1 & $<0.01$ & 1.005 & $1.003-1.007$ \\
VEGF & $<0.01$ & 1.016 & $1.004-1.029$ \\
Multivariate analysis & & & \\
Age & .011 & 1.134 & $1.030-1.249$ \\
Hypertension & .004 & 10.798 & $2.174-53.622$ \\
Diabetes & .019 & 11.630 & $1.487-90.941$ \\
TC & .058 & 2.416 & $0.971-6.010$ \\
EPCs & $<0.01$ & 0.067 & $0.023-0.198$ \\
SDF-1 & .001 & 1.007 & $1.003-1.011$ \\
\hline
\end{tabular}

early stroke recurrence in NICE, mainly divided into clinical predictors [9-12], imaging predictors [13-15] and biomarker predictors [16-18], in which clinical predictors have been studied the most abundantly but not a single biomarker predictor has been found for clinical application.

Studies have shown that approximately 5 to $25 \%$ of the endothelium in neovascularization after cerebral infarction is derived from EPCs [19]. EPCs are considered to be immature endothelial cells that can promote angiogenesis. The most widely accepted phenotypically defined EPC is the coexpression of the cell-surface markers CD34 and VEGFR2 [20]. Some studies have also suggested that low circulating EPC levels were independently predictive of severe neurological impairment (National Institutes of Health Stroke Scale $\geq 12$ ) at $48 \mathrm{~h}$ and of combined major adverse clinical outcomes on day 90 after ischemic stroke [21].

Studies from Ghani showed that patients with fewer EPCs in their peripheral blood are more likely to develop cerebrovascular disease. They proposed that the number of peripheral blood EPCs can be used as an indicator of vascular repair function and an independent predictor of cardiovascular and cerebrovascular events [22]. Some scholars have suggested that circulating EPCs and SDF-1 levels may predict the severity and prognosis of patients with ischemic stroke. Higher levels of EPCs in peripheral blood indicate a smaller infarct volume in stroke and a slower development rate. Compared with cerebral infarction of small blood vessels, the level of circulating EPCs in patients with cerebral infarction with large vascular disease is low, and the lower level of circulating EPCs at admission indicates a poor prognosis within 6 months [23-26]. Regarding the study of EPCs, previous studies have been conducted on patients with cerebral infarction and myocardial infarction, and there are few studies on patients with TIA and minor stroke. Scholars still pay little attention to the application of EPCs in patients with nondisabling ischemic cerebrovascular events.

This research is based on 153 patients with TIA and minor stroke. The data showed that patients in the HR-NICE group were older and included more patients with hypertension and diabetes. The reason for this is related to whether the patients were classified as high-risk nondisabling ischemic cerebrovascular events

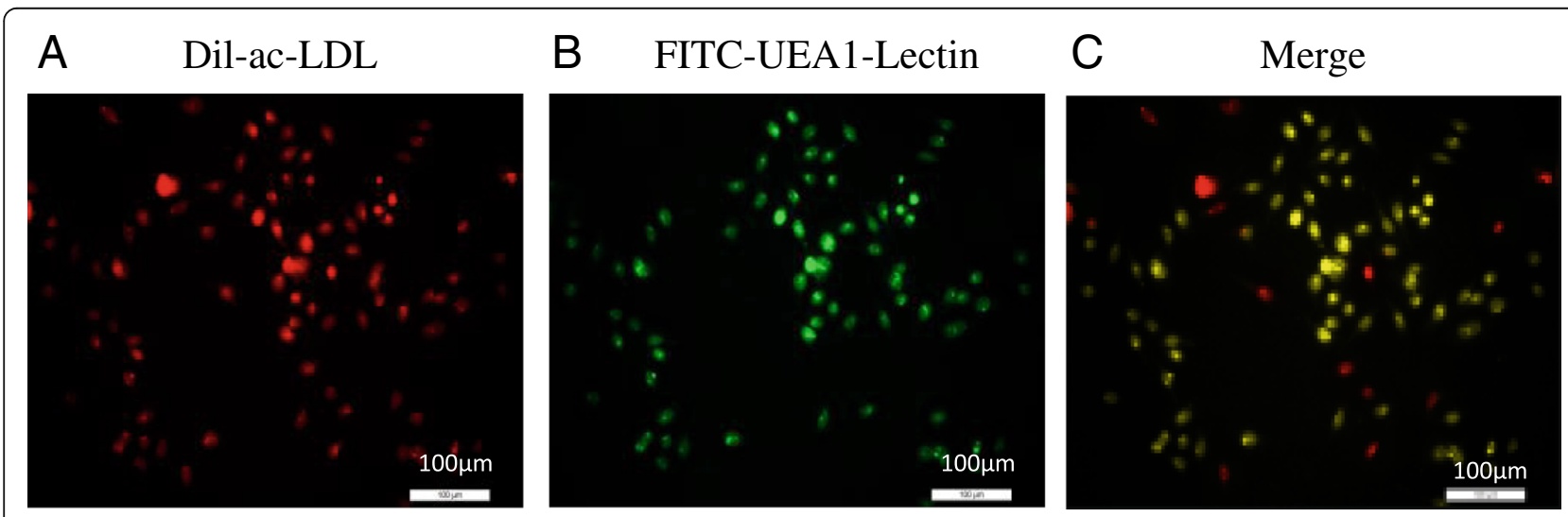

Fig. 2 EPC double phagocytosis experiments showed that FITC-Lectin was positive for green fluorescence (Fig. 2a), DIL-acLDL was positive for red fluorescence (Fig. 2b), and double-labeled cells were yellow for the differentiation of EPCs (Fig. 2c) 

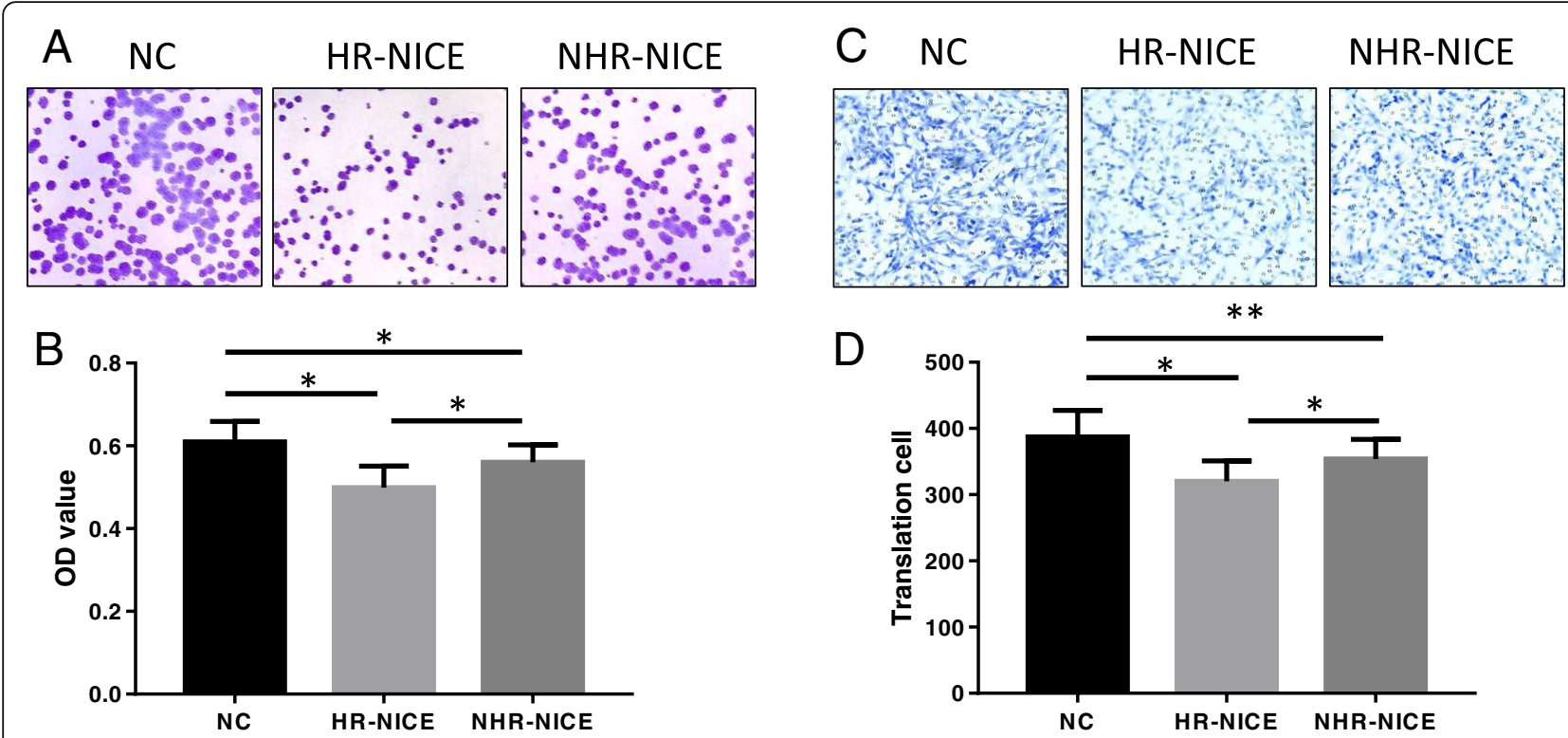

Fig. 3 Peripheral blood was isolated and cultured for $48 \mathrm{~h}$ in EPCS. A colony assay (Fig. 3a, magnification $\times 200$ ) and MTT assay (Fig. 3b) were used to detect the proliferation ability of each group. The Transwell assay was used to test the cell migration ability (Fig. 3c, magnification $\times 100$ ); and the counting chart is shown in Fig. 3d. The cell migration ability of the HR-NICE group was weakened $(P<0.01)$. The cell migration ability of the NHR-NICE group was weaker than that of the NC group, and the difference was significant $(P<0.05)$. ${ }^{*} P<0.01$, ${ }^{* *} P<0.05$

using the $\mathrm{ABCD} 2$ scoring criteria because age, hypertension, and diabetes were some of the indicators of the $\mathrm{ABCD} 2$ score. However, peripheral blood triglycerides, total cholesterol, and low-density lipoprotein were also higher in the HR-NICE group and more risk factors for stroke were found in this group as well.

At $24 \mathrm{~h}$ after onset, the HR-NICE group had lower circulating EPC levels and higher serum SDF-1 and VEGF levels, which may be more related to the risk factors of this group of patients and is consistent with reports that showed more risk factors with lower EPC levels [27, 28]. Studies have reported that an increased probability of future cerebrovascular events did not occur in these patients with elevated EPCs in the first attack of TIA [4], which is consistent with higher levels of EPCs in the NHR-NICE group in this study. In other words, the reduction in EPCs may increase the risk of recurrent stroke in NICE patients. After adjusting for age, BMI, hypertension, diabetes, smoking, triglycerides, total cholesterol, low-density lipoprotein, homocysteine, EPCs, SDF-1, and VEGF, multivariate logistic regression analysis showed that age, hypertension, diabetes, EPCs, and SDF-1 are independent risk factors for HR-NICE. The results of the proliferation and migration of EPCs suggested that the proliferation and migration abilities of the HR-NICE group and NHR-NICE group were weaker than those of the NC group and that those of the HR-NICE group was worse. Compared with the NHR-NICE group, the number of circulating EPCs in the HR-NICE group decreased, and the proliferation and migration ability decreased as well. In terms of vascular endothelial injury and repair ability, basic diseases such as hypertension, diabetes, and hyperlipidemia could lead to a decrease in the number and quality of EPCs. The intermediate link between various risk factors and ischemic stroke is EPCs. Therefore, EPCs may be a type of more direct assessment to evaluate the high risk of NICE in the early phase and to predict prognosis. It is speculated that the cause of high stroke risk in the HR-NICE group is related to the decrease in the number of EPCs and the weakening of proliferation and migration.

It is well known that underlying diseases such as hypertension, diabetes, and hyperlipidemia are the cause of atherosclerosis and are risk factors for ischemic cerebrovascular disease. Studies have shown that the abovementioned cardiovascular and cerebrovascular risk factors can lead to a decrease in the quantity and quality of EPCs [27, 28], and the number and function of EPCs directly affects the repair ability after vascular injury. Therefore, the level and function of circulating EPCs in the ischemic brain play an important role in the pathogenesis of vascular disease.

Merwick found that patients with an ABCD2 score of less than 4 had a recurrence rate of $4.1 \%$ and suggested that the ABCD2 score should be combined with other criteria to assess the risk of recurrent stroke in TIA patients [10, 29]. Although EPCs are rarely used in clinical practice, such as stem cell transplantation and endothelial progenitor cell-seeded stents [20,30, 31], EPCs may be an indicator to predict the risk of TIA and minor 
stroke. Therefore, EPCs and SDF-1 may be used as new biomarkers to predict the risk of early stroke recurrence in NICE.

\section{Conclusions}

For TIA and minor stroke patients, circulating EPCs and serum SDF-1 concentrations can be used to prognose HR-NICE. Factors that lead to high-risk NICE might be relevant to the decrease of the proliferation and migration of circulating EPCs.

\section{Abbreviations}

ACl: Acute cerebral infarction; BMI: Body mass index; CEPCs: Circulating endothelial progenitor cells; Cl: Confidence Interval; ELISA: Enzyme-linked immunosorbent assay; EPCs: Endothelial progenitor cells; FCM: Flow cytometry; HCY: Homocysteine; HR-NICE: High-risk nondisabling ischemic cerebrovascular event; LDL: Low Density Lipoprotein; NC: Normal Control; NHR-NICE: Non-high-risk nondisabling ischemic cerebrovascular events; NICE: Nondisabling ischemic cerebrovascular events; OR: Odds Ratio; SDF1: Serum stromal cell-derived factor-1; TC: Total Cholesterol; TG: Triglyceride TIA: Transient ischemic attack; VEGF: Vascular endothelial growth factor

\section{Acknowledgements}

We thank all the people and patients who participated in this study.

\section{Funding}

This work was funded by the Chongqing Municipal Health Bureau Medical Research Project (2011-2-271), Chongqing Municipal Health Bureau Traditional Chinese Medicine Science and Technology Key Project (ZY20131027), and Chongqing Yongchuan Natural Science Fund Project (Ycstc,2016nc5024). The funding bodies mentioned above had no role in the design of the study nor the collection, analysis and interpretation of the data and have no access to patient information. The funding body did not participate in writing the manuscript. The study protocol has undergone peer-review process by the funding bodies.

\section{Availability of data and materials}

The datasets used or analyzed during the current study are available from the corresponding author on reasonable request.

\section{Authors' contributions}

WZ was responsible for the concept and design of the study, data collection and analysis and the first draft of the paper and further manuscript. YL was responsible for concept and design of the study, the data analysis and interpretation. JL, LbZ and LYH were jointly involved in case collection and experimental operations

\section{Ethics approval and consent to participate}

We obtained ethical approval for this study from the Medical and Health Research Ethics Committee in Yongchuan Hospital of Chongqing Medical University, the.

current study was carried out according to Declaration of Helsinki. Loca legal and regulatory authorities as well as the medical secrecy will be followed. If the patient has consciousness disorder or aphasia, the decision cannot be made by themselves, the consent form can be signed by the patient's legal proxies. Before enrollment, all patients or there legal proxies were given detailed information about the aims, scope and possible consequences of the study by a physician. No diagnostic or interventional procedures required for the clinical trial. Written informed consent was obtained from all study participants.

\section{Consent for publication}

Not applicable.

\section{Competing interests}

The authors have no conflict of interest to declare.

\section{Publisher's Note}

Springer Nature remains neutral with regard to jurisdictional claims in published maps and institutional affiliations.

\section{Author details}

'Department of Neurology, Yongchuan Hospital of Chongqing Medical University, Chongqing 402160, China. ${ }^{2}$ Central Laboratory, Chongqing Key Laboratory of Cerebrovascular Disease Research, Yongchuan Hospital of Chongqing Medical University, Chongqing 402160, China. ${ }^{3}$ Department of Neurology, The First Affiliated Hospital of Chongqing Medical University, Chongqing 400016, China. ${ }^{4}$ Department of Neurology, Second Peoples Hospital of Chengdu, Chengdu 610000, Sichuan Province, China.

Received: 11 October 2018 Accepted: 1 February 2019

Published online: 12 February 2019

\section{References}

1. Wang Y, Zhao X, Jiang Y, et al. Prevalence,knowledge,and treatment of transient ischemic attacks in China. Neurology. 2015;84(23):2354-61.

2. Kim YS, Baek W, Kim MK, et al. Association between serum stromal cellderived factor-1a and long-term outcome of acute ischemic stroke. Eur Neurol. 2012;67(6):363-9.

3. Deng Y, Wang J, He G, et al. Mobilization of endothelial progenitor cell in patients with acute ischemic stroke. Neurol Sci. 2018:39(3):437-43.

4. Meamar R, Nikyar H, Dehghani L, et al. The role of endothelial progenitor cells in transient ischemic attack patients for future cerebrovascular events. Res Med Sci 2016;21:47.

5. Liu L, Wang D, Wong KS, et al. Stroke and stroke care in China:huge burden, significant workload, and a national priority. Stroke. 2011;42(12):3651-4.

6. Khan SS, Solomon MA, McCoy JP Jr. Detection of circulating endothelial cells and endothelial progenitor cells by flow cytometry. Cytometry B Clin Cytom. 2005;64(1):1-8.

7. Zeng W, Yuan W, Li L, et al. The promotion of endothelial progenitor cells recruitment by nerve growth factors in tissue-engineered blood vessels. Biomaterials. 2010;31(7):1636-45.

8. Fischer $\mathrm{U}$, Baumgartner $\mathrm{A}$, Arnold $\mathrm{M}$, et al. What is a minor stroke? Stroke. 2010:41(4):661-6.

9. Yang J, Fu JH, Chen XY, et al. Validation of the ABCD2 score to identify the patients with high risk of late stroke after a transient ischemic attack or minor ischemic stroke. Stroke. 2010;41(6):1298-300.

10. Johnston SC, Rothwell PM, Nguyen-Huynh MN, et al. Validation and refinement of scores to predict very early stroke risk after transient ischaemic attack. Lancet. 2007;369(9558):283-92.

11. Coutts SB, Eliasziw M, Hill MD, et al. An improved scoring system for identifying patients at high early risk of stroke and functional impairment after an acute transient ischemic attack or minor stroke. Int J Stroke. 2008: 3(1):3-10

12. Giles MF, Albers GW, Amarenco $P$, et al. Addition of brain infarction to the $A B C D 2$ score (ABCD2I):a collaborative analysis of unpublished data on 4574 patients. Stroke. 2010;41(9):1907-13.

13. Zhang $C$, Zhao $X$, Wang $C$, et al. Prediction factors of recurrent ischemic events in one year after minor stroke. PLoS One. 2015:10(3):e0120105.

14. Horton M, Modi J, Patel SK, et al. Refinement of imaging predictors of recurrent events following transient ischemic attack and minor stroke. PLoS One. 2013;8(6):e65752.

15. Coutts SB, Modi J, Patel SK, et al. CT/CT angiography and MRI findings predict recurrent stroke after transient ischemic attack and minor stroke: results of the prospective CATCH study. Stroke. 2012;43(4):1013-7.

16. Li J Wang $Y$, Lin J, et al. Soluble CD40L is a useful marker to predict future strokes in patients with minor stroke and transient ischemic attack. Stroke. 2015;46(7):1990-2.

17. Lin J, Zheng H, Cucchiara BL, et al. Association of Lp-PLA2-a and early recurrence of vascular events after TIA and minor stroke. Neurology. 2015; 85(18):1585-91.

18. Li J, Wang Y, Wang D, et al. Glycated albumin predicts the effect of dual and single antiplatelet therapy on recurrent stroke. Neurology. 2015;84(13): 1330-6.

19. Asahara T, Kawamoto A. Endothelial progenitor cells for postnatal vasculogenesis. Am J Physiol Cell Physiol. 2004;287(3):C572-9.

20. Esquiva G, Grayston A, RA. Revascularization and Endothelial progenitor cells in stroke. Am J Physiol Cell Physiol. 2018. 
21. Yip HK, Chang LT, Change WN, et al. Level and value of circulating endothelial progenitor cells in patients after acute ischemic stroke. Stroke. 2008;39(1):69-74

22. Ghani U, Shuaib A, Salam A, et al. Endothelial progenitor cells during cerebrovascular disease. Stroke. 2005;36(1):151-3.

23. Chen Y, Lu B, Wang J, et al. Circulating CD133+ CD34+ progenitor cells and plasma stromal-derived factor-1Alpha: predictive role in ischemic stroke patients. J Stroke Cerebrovasc Dis. 2015;24(2):319-26.

24. Bogoslovsky T, Chaudhry A, Latour L, et al. Endothelial progenitor cells correlate with lesion volume and growth in acute stroke. Neurology. 2010; 75(23):2059-62.

25. Tsai NW, Hung SH, Huang CR, et al. The association between circulating endothelial progenitor cells and outcome in different subtypes of acute ischemic stroke. Clin Chim Acta. 2014;427:6-10.

26. Schutt RC, Burdick MD, Strieter RM, et al. Plasma CXCL12 levels as a predictor of future stroke. Stroke. 2012;43(12):3382-6.

27. Hill JM, Zalos G, Halcox JP, et al. Circulating endothelial progenitor cells vascular function and cardiovascular risk. N Engl J Med. 2003;348(7):593-600

28. Makino H, Miyamoto Y, Kikuchi-Taura A, et al. Decreased levels of circulating CD34+ cells are associated with coronary heart disease in Japanese patients with type 2 diabetes. J Diabetes Investig. 2015;6(4):473-8.

29. Merwick A, Albers GW, Amarenco P, et al. Addition of brain and carotid imaging to the $A B C D$ (2) score to identify patients at early risk of stroke after transient ischaemic attack:a multicentre observational study. Lancet Neurol. 2010;9(11):1060-9.

30. Liao S, Luo C, Cao B, et al. Endothelial progenitor cells for ischemic stroke: update on basic research and application. Stem Cells Int. 2017;2193432:2017.

31. Zhou Z, Shi S, Song M, et al. Development of transgenic endothelial progenitor cell-seeded stents. J Biomed Mater Res A. 2009;91(2):623-8.

Ready to submit your research? Choose BMC and benefit from:

- fast, convenient online submission

- thorough peer review by experienced researchers in your field

- rapid publication on acceptance

- support for research data, including large and complex data types

- gold Open Access which fosters wider collaboration and increased citations

- maximum visibility for your research: over $100 \mathrm{M}$ website views per year

At $\mathrm{BMC}$, research is always in progress.

Learn more biomedcentral.com/submissions 